\title{
New tricks for metastasis-associated macrophages
}

\author{
Bin-Zhi Qian and Jeffrey W Pollard*
}

\begin{abstract}
Recent studies on breast cancer lung metastasis have identified a new mechanism of tumor cell survival via signaling provided by metastasis-associated macrophages. Targeting these specialized host immune cells and their specific signals provides an attractive and potential therapeutic approach for treating the disease.
\end{abstract}

Metastasis is the major cause of breast cancer lethality. In target organs, a series of events are required for the establishment of metastatic tumor cells. These events include: adherence to the blood vessel, extravasation, survival, establishment of micrometastases, and persistent growth into macrometastases. While tumor cell intrinsic factors can enhance metastatic efficiency and site selection [1], metastasis also relies on interactions between spreading tumor cells and host factors in the target organ [2]. These host factors include cytokines/ growth factors, extracellular matrix, platelets, and different stromal and immune cells [2]. Particularly, a population of metastasis-associated macrophages has been identified that promotes breast cancer metastasis [3]. These cells, derived from a subset of inflammatory monocytic precursor cells, promote tumor cell extravasation through vascular endothelial growth factor production and their subsequent survival and growth [3,4].

Chen and colleagues have provided a new mechanism for the metastasis-promoting function of metastasisassociated macrophages through their adherence to tumor cells that provides survival signals to the tumor cells [5]. Previous studies from this group compared gene expression changes of subclones of a human mammary carcinoma cell line, MDA-MB-231, which have differential metastatic efficiencies to target organs when introduced into the circulation of immune-deficient mice [6]. The hypothesis being that certain genes are

${ }^{*}$ Correspondence: jeffrey.pollard@einstein.yu.edu

Department of Developmental and Molecular Biology, Albert Einstein College of Medicine, Bronx, NY 10461, USA preferentially expressed by cells with higher metastatic efficiency and that if their expression is correlated with poor prognosis and metastatic disease, this gene is likely to contribute to the metastatic process in patients. Based on this idea, a lung metastasis gene expression signature was identified by comparing subclones selected for lung metastasis with the parental MDA-MB-231 line and those subclones selected for metastasis to bone or brain [6]. The focus of the current study by Chen and colleagues was vascular cell adhesion molecule-1 (VCAM-1), one of the upregulated genes from this lung signature. VCAM-1 is a cell-cell adhesion protein that binds to $\alpha_{4}$-integrins $\left(\alpha_{4} \beta_{1}\right.$ or $\left.\alpha_{4} \beta_{7}\right)$. During inflammation, $\alpha_{4}$-integrins expressed by leukocytes interact with VCAM-1 in the endothelium, which promotes leukocyte recruitment. Such $\alpha_{4}$-integrin-VCAM-1 interaction also plays important roles in recruiting and maintaining hematopoietic stem and progenitor cells in the bone marrow [7].

Chen and colleagues showed that the VCAM-1 on tumor cells did not enhance tumor transendothelial migration and had no effect on the early recruitment of immune cells including macrophages. VCAM-1 interactions were thus not important for tumor arrest or extravasation. Instead, VCAM-1 enhanced longer-term tumor cell survival and growth of lung metastases through interaction with $\alpha_{4}$-integrin expressed by metastasisassociated macrophages (Figure 1). This cell-cell adhesion provides survival signals to the tumor cells by clustering of the cell surface VCAM-1. Through its cytoplasmic domain, clustered VCAM-1 recruited phosphorylated ezrin - which in turn recruits phosphoinositide-3-kinase and activates Akt that provides the survival signal in the tumor cell. VCAM-1 also supported the re-seeding of metastatic cells from the lung into the primary tumor in a process known as self-seeding previously described by this group [8]. The study also showed that high levels of VCAM-1 correlate with increased leukocyte infiltration in the primary tumors from breast cancer patients. VCAM-1 expressions were also elevated in breast cancer metastases to lung and bone, but not in those to brain, and high levels of VCAM-1 correlated with tumors with high leukocytic infiltration. However, VCAM-1 overexpression did not enhance metastasis of MDA-MB-231 cells to the bone. In summary, the results of Chen and colleagues establish that metastasis-associated macrophages 


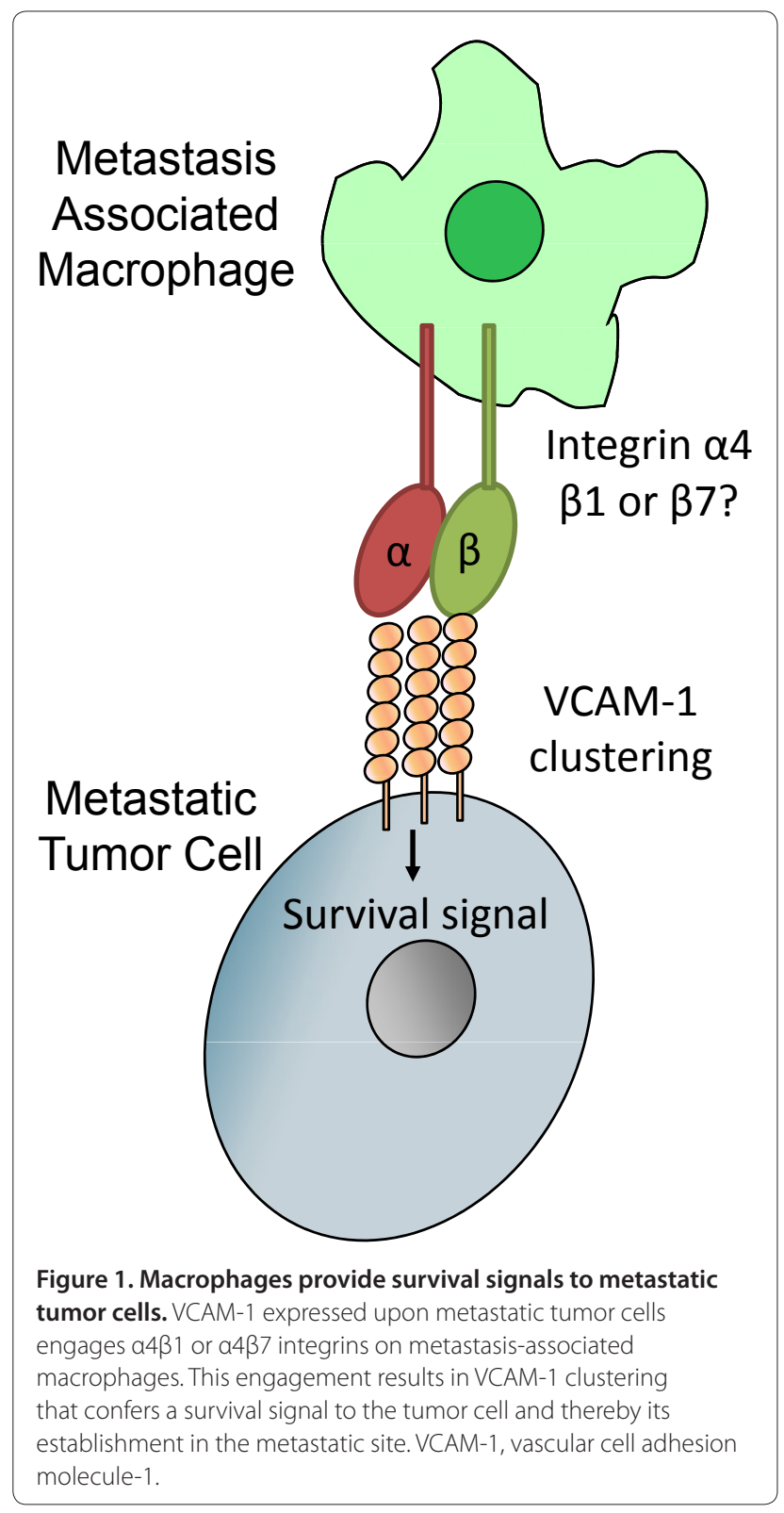

provide survival and growth signals to metastatic tumor cells through direct binding of $\alpha_{4}$-integrin to VCAM-1 expressed by tumor cells.

Using a different line of dormant breast tumor cells, another recent study showed that VCAM-1 enhanced the propagation of tumor cells in the bone through osteoclast activation [9]. This may suggest cell-line-specific mechanisms of VCAM-1 in bone metastasis. Given the critical role of VCAM-1 in maintaining hematopoietic stem cells [7], direct targeting of this molecule should be taken with caution. However, it is attractive to target metastasisassociated macrophages and their interaction with tumor cells to treat metastatic disease. Specific mechanisms that control the recruitment and tumor-promoting functions of these cells need to be identified to develop novel therapeutic approaches for use alone or in combination with conventional treatments that target tumor cells. Such strategies may provide effective therapies for the treatment of metastatic disease.

\section{Abbreviations}

VCAM-1, vascular cell adhesion molecule-1.

\section{Competing interests}

The authors declare that they have no competing interests.

Published: 19 July 2012

\section{References}

1. Chiang AC, Massague J: Molecular basis of metastasis. N Eng/J Med 2008, 359:2814-2823.

2. Joyce JA, Pollard JW: Microenvironmental regulation of metastasis. Nat Rev Cancer 2009, 9:239-252.

3. Qian B, Deng Y, Im JH, Muschel RJ, Zou Y, Li J, Lang RA, Pollard JW: A distinct macrophage population mediates metastatic breast cancer cell extravasation, establishment and growth. PLoS ONE 2009, 4:e6562.

4. Qian BZ, Li J, Zhang H, Kitamura T, Zhang J, Campion LR, Kaiser EA, Snyder LA, Pollard JW: CCL2 recruits inflammatory monocytes to facilitate breasttumour metastasis. Nature 2011, 475:222-225.

5. Chen Q, Zhang XH, Massague J: Macrophage binding to receptor VCAM-1 transmits survival signals in breast cancer cells that invade the lungs. Cancer Cell 2011, 20:538-549.

6. Minn AJ, Gupta GP, Siegel PM, Bos PD, Shu W, Giri DD, Viale A, Olshen AB, Gerald WL, Massague J: Genes that mediate breast cancer metastasis to lung. Nature 2005, 436:518-524.

7. Nervi B, Link DC, DiPersio JF: Cytokines and hematopoietic stem cell mobilization. J Cell Biochem 2006, 99:690-705.

8. Norton L, Massague J: Is cancer a disease of self-seeding? Nat Med 2006, 12:875-878.

9. Lu X, Mu E, Wei Y, Riethdorf S, Yang Q, Yuan M, Yan J, Hua Y, Tiede BJ, Lu X, Haffty BG, Pantel K, Massague J, Kang Y: VCAM-1 promotes osteolytic expansion of indolent bone micrometastasis of breast cancer by engaging $a_{4} \beta_{1}$-positive osteoclast progenitors. Cancer Cell 2011, 20:701-714.

doi:10.1186/bcr3143

Cite this article as: Qian BZ, Pollard JW: New tricks for metastasis-associated macrophages. Breast Cancer Research 2012, 14:316. 